Fecha de recepción: abril 2020 Fecha de aceptación: mayo 2020 Versión final: junio 2020

\section{De la producción de experiencias \\ a la exhibición de arquitectura (1957-1970). Situacionistas, utopistas y posmodernistas}

Carolina Corti ${ }^{(1)}$

\begin{abstract}
Resumen: Este trabajo recorre el lugar que tuvo la exhibición de arquitectura como fenómeno ligado a las nociones de experiencia, percepción y lenguaje. Este camino histórico atraviesa algunos hitos importantes para la temática, como la creación del movimiento Internacional Situacionista, el legado del grupo Archigram y los nuevos debates a la luz de los paradigmas posmodernistas. El artículo constituye el resultado de una tesis de postgrado que plantea la importancia de analizar la producción de la arquitectura -usualmente materializada a través del "hacer arquitectónico"-abordando sus significados por fuera de la materialización de la obra.
\end{abstract}

Palabras clave: Arquitectura - Exhibiciones - Posmodernidad - Situacionismo.

[Resúmenes en inglés y portugués en la página 103]

(1) Magíster por la Facultad de Arquitectura, Diseño y Urbanismo de la Universidad de Buenos Aires. Egresada de la Maestría en Diseño y Comunicación (DICOM).

La exposición arquitectónica tiene una larga historia museológica, gran parte de la cual se ha entrelazado, acercándose y alejándose, a los paradigmas dominantes regidos por las "Bellas Artes" y las Artes Plásticas o Artes Visuales. La imagen como copia fue un concepto muy difundido en el Renacimiento con el método de la perspectiva. Así, la representación mimética predominaría en la historia del arte hasta avanzado el siglo XIX, para ser abandonada por las vanguardias estéticas del siglo XX, a fin de asignarle a la imagen una mayor autonomía (Fiorini y Schilman, 2009).

$\mathrm{Al}$ igual que las exposiciones de pinturas y esculturas, la arquitectura a menudo se ha representado en exposiciones pictóricas -en bocetos de cuadros y fotografías- y en la representación a escala de modelos sobre zócalos y en vitrinas. En consecuencia, la exposición arquitectónica como propuesta interdisciplinaria y revaloración del discurso disciplinar se basó en gran medida en el paradigma bien establecido de las exhibiciones de "Bellas Artes", centradas en el producto antes que en el proceso. Sin embargo, desde su institucionalización en la escena emergente de los museos públicos de finales del siglo XVIII, la arquitectura, en tanto sujeto y objeto de muestra museológica, generó una serie de interrogantes. 

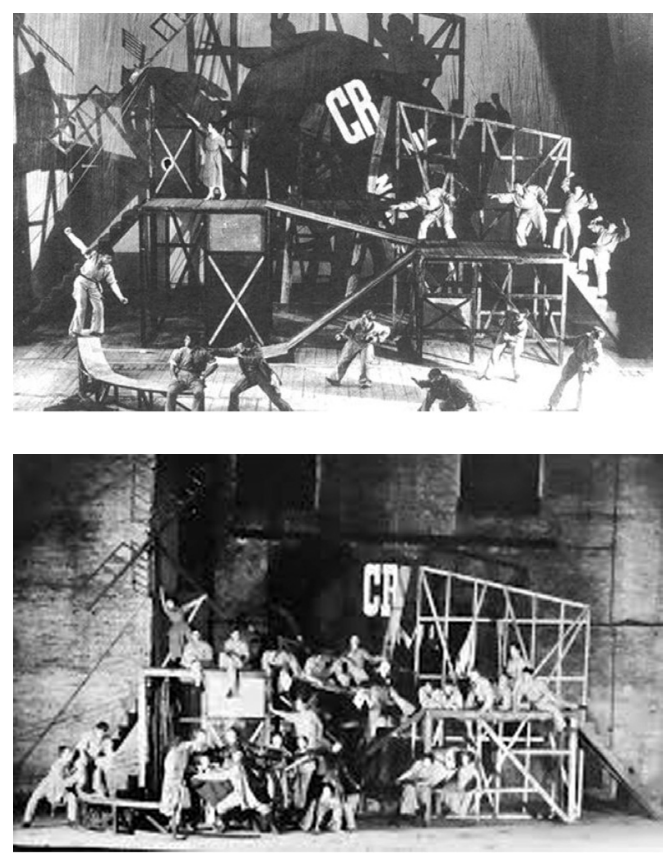

Figuras 1 y 2. Las representaciones teatrales sirvieron a los arquitectos para poner a prueba sus ideas antes de construir los edificios, sirviendo como antecesores de los laboratorios experimentales de arquitectura de Archigram. Imágenes de la representación de la artista rusa Lyubov Popova para "The Magnanimous Cuckold".

En este sentido, según Carter (2012), una particularidad distingue a las muestras de arquitectura de las de Bellas Artes, y es que "a diferencia de las exhibiciones de bellas artes, las exhibiciones arquitectónicas generalmente no pueden mostrar un trabajo en su totalidad, y esta distinción fundamental plantea ciertos desafíos perdurables para la curaduría de la arquitectura"1 (p. 32).

Cierto es que los espacios públicos destinados a la exhibición, como museos, galerías y salas, no existieron hasta finales del siglo XVII y le tomó a la arquitectura otros cien años más para encontrar su camino en estos círculos de expresión, recorridos diversos de trayecto espacial y ejercicio de la disciplina. Mientras tanto, los arquitectos utilizaban otros espacios, como las representaciones teatrales, para poner a prueba sus ideas antes de construir los edificios, pudiendo considerarse así los antecesores de los laboratorios experimentales de arquitectura (Kossak, 2009)2 (Ver Figuras 1 y 2).

\section{Situacionistas}

Entre los años sesenta y setenta del siglo pasado, tuvo lugar un momento en el que una nueva generación de arquitectos se vio deleitada y convocada por las nociones de percep- 
ción, performance y experiencia ${ }^{3}$. El foco se tornaba hacia la cuestión social y una de estas actividades sociales era la noción de obra.

La preocupación académica, creativa y crítica de esta nueva generación, coincide con una etapa histórica en la que no sólo en las artes sino también en los discursos sociales y más ampliamente, en la emergente teoría de la comunicación y la cultura, la construcción de una imagen de autor enlaza con las condiciones teóricas, históricas e institucionales para el surgimiento del famoso tópico que pronunciara Roland Barthes en $1968^{4}$. Sucintamente, la fórmula barthesiana sobre "la muerte del autor", propone generar una nueva recepción de la obra de arte donde lo que importa es la lectura de la obra, y no lo que pueda decir o afirmar el autor de la misma. En otros términos, se trata del resurgimiento del lector como figura hegemónica y de la posibilidad de una escritura/producción/creación múltiple, desdoblada y ubicua. Se trató de un momento histórico de crisis que atravesó discursos y artes y en el que se volvió imperativo acabar con la "tiranía del autor" para dar lugar al intérprete y al lector/público/audiencia/receptor como actor clave y constitutivo de la obra misma ${ }^{5}$.

Es en este marco de límites difusos y expandidos que la audiencia se tornó participativa e incluso productora de la obra. El ámbito artístico, surgido del cruce de diversas disciplinas -como las artes visuales, la música, la danza, el teatro, la poesía, el cine experimental, el videoarte- es descripto por Pinta (2012) como una amplia gama de experiencias caracterizada por dos cualidades fundamentales. Por un lado, prima la idea de evento y acción; por otro, la concepción de la producción artística se desplaza del resultado (obra de arte) al proceso:

La acción puesta en juego busca desarticular lo cotidiano, exponer lo prohibido y/o lo banal, provocar la repulsión y la atracción de zonas no visibles en las prácticas y los discursos sociales. El artista devenido performer ostenta no solo su presencia física, sino también la propia experiencia biográfica interpelando de forma directa al espectador y su propia experiencia de vida. En este sentido, la performance busca capturar las tensiones políticas e históricas de su propio tiempo y amenazar el statu quo (Pinta, 2012, p. 188).

Los situacionistas como Debord (1958) fueron el antecedente a este interés en la "obra" y las derivas o "juegos" en el contexto de la ciudad. En efecto, así como los sistemas eran una obsesión del siglo XIX, la percepción lo fue para el siglo XX (O’Doherty, 1986, p. 61). Entre 1957 y 1972, el movimiento artístico y político conocido como Internacional Situacionista (IS) trabajó agresivamente para subvertir la ideología conservadora del mundo occidental. El ataque generalizado del movimiento contra las instituciones y los valores del "establishment" dejó su huella en la izquierda libertaria, la contracultura, los acontecimientos revolucionarios de 1968 y los fenómenos más recientes del punk al posmodernismo. Según los situacionistas, el profesionalismo benigno de la arquitectura y el diseño había llevado a una esterilización del mundo que amenazaba con eliminar cualquier sentido de espontaneidad o juego. A finales de los años cincuenta, movimientos como el arte pop británico y estadounidense y el francés Nouveau Réalisme se habían interesado intensamente en la vida cotidiana, el espacio y la cultura de masas. 

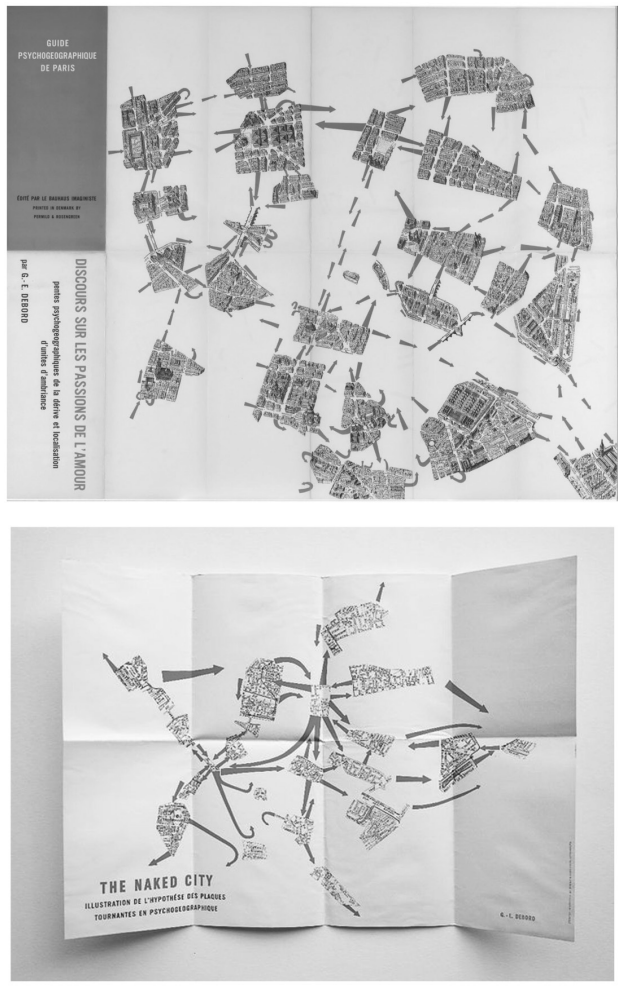

Figuras 3 y 4. La deriva situacionista se presenta como una técnica de paso ininterrumpido a través de ambientes diversos. El concepto está ligado a la afirmación de un comportamiento lúdicoconstructivo que la opone en todos los aspectos a las nociones clásicas de viaje y de paseo.

La IS tenía como objetivo convertir este interés en una revolución, al nivel de la ciudad misma. Su principio para la reorganización de las ciudades era simple y seductor: dejar que los propios ciudadanos decidieran qué espacios y en qué arquitectura querían vivir, y cómo deseaban vivirlos. Esto minaría instantáneamente los poderes del Estado, la burocracia, el capital y el imperialismo, revolucionando así la vida cotidiana de las personas (Sadler, 1999). El concepto situacionista de "situación construida" pretende sustituir la representación artística por la realización experimental de la energía artística en los ambientes de lo cotidiano (Bourriaud, 2006, p. 106). Entre los diversos procedimientos situacionistas, la "deriva" se presenta como una técnica de paso ininterrumpido a través de ambientes diversos. El concepto está ligado "al reconocimiento de efectos de naturaleza psicogeográfica y a la afirmación de un comportamiento lúdico-constructivo que la opone en todos los aspectos a las nociones clásicas de viaje y de paseo (...)” (Debord, 1958, pp. 1-2). (Ver Figuras 3 y 4 ). El situacionismo como movimiento de vanguardia se disolvió en 1972. Los esfuerzos de esta corriente de pensamiento por conjugar los discursos y las prácticas estéticas y políticas durante el siglo XX, pusieron en crisis y cuestionaron la noción de una representación 
separada de lo real, la alienación y cosificación como estado de vida, ofreciendo una alternativa revolucionaria a la cultura dominante. Sus estudios sobre la generación de experiencias y la construcción de ambientes alternativos convocaron el ideal de las vanguardias como medios de intervención en las sociedades espectacularizadas de consumo.

\section{Utopistas}

En los 50s y 60s, las vanguardias abandonaron abiertamente las certezas intelectuales y artísticas del materialismo histórico a fin de reconocer la diversidad y el desorden del mundo material y de las experiencias psicológicas y sociales. Los nuevos órdenes de la sociedad ejercían su efecto sobre las prácticas culturales, entre ellas la museología, donde se evidencia una evolución en las tradiciones de las exhibiciones arquitectónicas que implicó un movimiento desde la reconstrucción de edificios históricos y monumentales a gran escala ${ }^{6}$, a la exhibición de dibujos y modelos representativos de obras arquitectónicas (Blau, 1998). Este cambio significó un modificación de la intención de capturar "la experiencia de un edificio a gran escala" (Miller, 2007, p. 98) para comunicar no solo su apariencia sino también la experiencia del mismo. Este nuevo paradigma expositivo generaba un alto nivel de interactividad que los curadores orquestaron entre los visitantes y los objetos en exhibición. En este contexto, la arquitectura sería definitivamente transformada más allá de lo imaginable por la tecnología de la era espacial, la computación, la producción en serie y las demandas de la nueva sociedad de consumo.

El caso del grupo Archigram ${ }^{7}$ es un ejemplo de este momento en el cual la arquitectura tuvo la posibilidad de tomar un rumbo diferente al de aquel momento, en el que algunos arquitectos se preocuparon por cuestiones ajenas a la obra misma en un contexto que remitía a la época de la Utopía de los sesenta. Archigram se constituyó a principios de los años sesenta con el objetivo de repensar la arquitectura en relación a las ciudades y las nuevas tecnologías de información, movimiento y percepción.

Los principales miembros del grupo fueron Peter Cook, Jhoana Mayer, Warren Chalk, Ron Herron, Dennis Crompton, Michael Webb y David Greene. Si bien nunca llegaron a construir nada, sus obras ofrecían visiones seductoras de una glamorosa era futura de la máquina; sin embargo, los temas sociales y ambientales no eran lo suficientemente realistas, dándole a estos proyectos el sello de "utópicos". Estaban influenciados por pensadores radicales de mediados del siglo XX, como Bruno Taut, Walter Gropius y Buckminster Fuller (Ver Figuras 5 y 6 ).

Los miembros de Archigram fueron provocativos en su deseo de repensar y reconfigurar la relación entre sociedad y arquitectura, centrándose principalmente en la relación entre las ciudades y las nuevas tecnologías de información, movimiento y percepción. Su contribución particular a la crítica del modernismo fue centrarse en lo urbano, lo popular, lo efímero y la idea de la arquitectura basada en la necesidad. Su importancia se reconoció formalmente en 2002 cuando Archigram recibió la Medalla de Oro Real del Royal Institute of British Architects, a pesar de que generalmente está reservada para arquitectos que han producido una gran cantidad de proyectos construidos. 

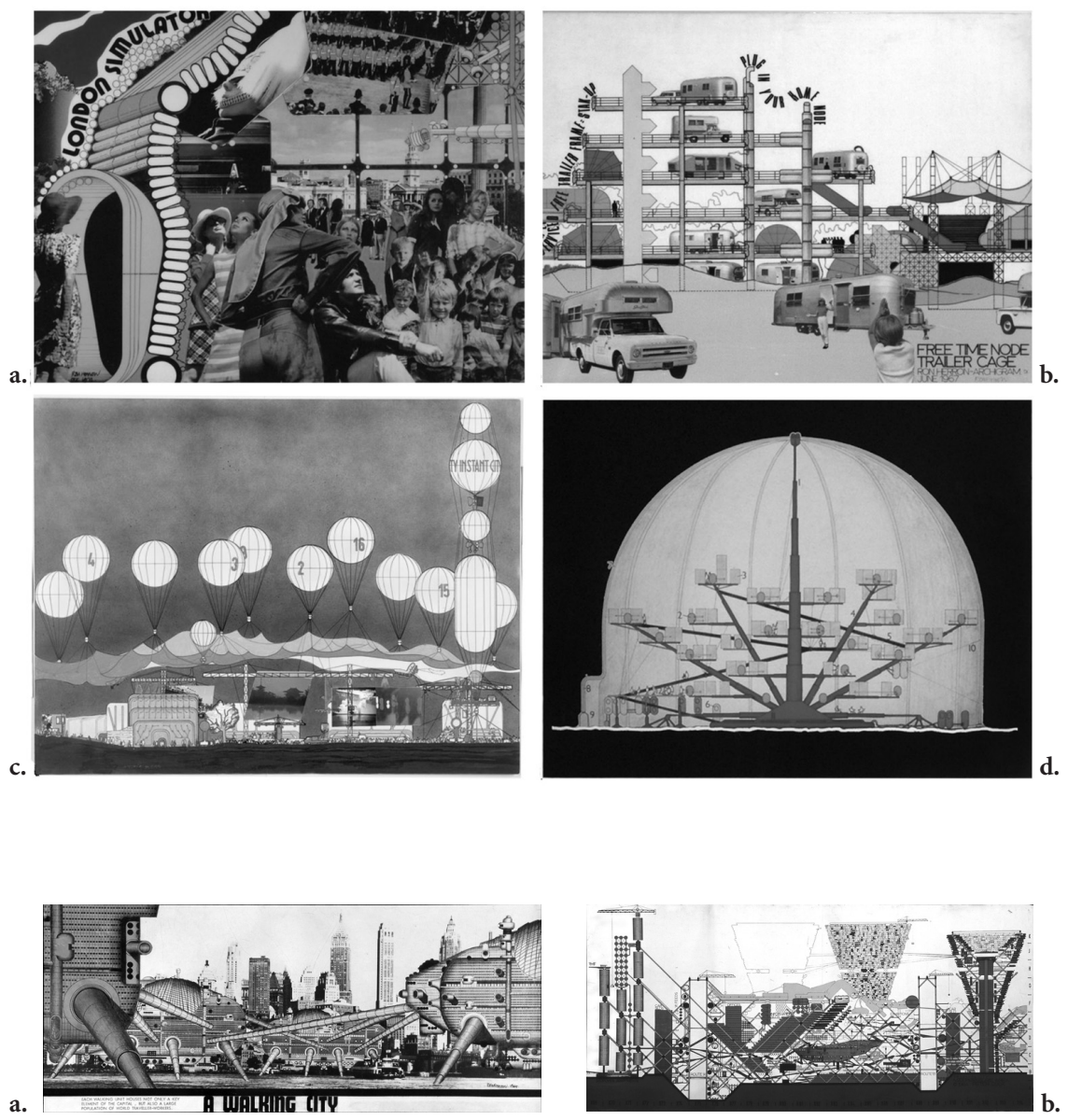

Figura 5 (arriba). a/ “Tuning London”, 1972. Proyecto especulativo que muestra aumentos graduales, crecimiento y cambio en Londres, mostrada con una sola tira de "dibujos animados" a través de la ciudad. b/ "Free time Node", 1966. Propuesta especulativa para una estructura de expansión/contratación para prestar servicio a casas rodantes, diseñada para una sociedad con una semana laboral de 2-3 días. c/ "Instant City", 1978. Proyecto de investigación especulativa que explora las posibilidades de inyectar dinámica metropolitana en otras áreas a través de eventos temporales, estructuras, instalaciones móviles y tecnología de la información. d/ "Blow-out Village", 1966. Propuesta especulativa para una aldea móvil utilizando aerodeslizadores, sistemas hidráulicos y tecnologías inflables.

Figura 6 (abajo). a/ “Plug-in City", 1964. Serie especulativa de propuestas para una ciudad controlada por computadora diseñada para el cambio con elementos intercambiables conectados a una megaestructura de servicio. b/ "Walking City", 1964. Propuesta de una infraestructura de ciudad nómade en la que los servicios públicos urbanos no estarían vinculados a una ubicación específica. Originalmente llamado "Cities: Moving". 

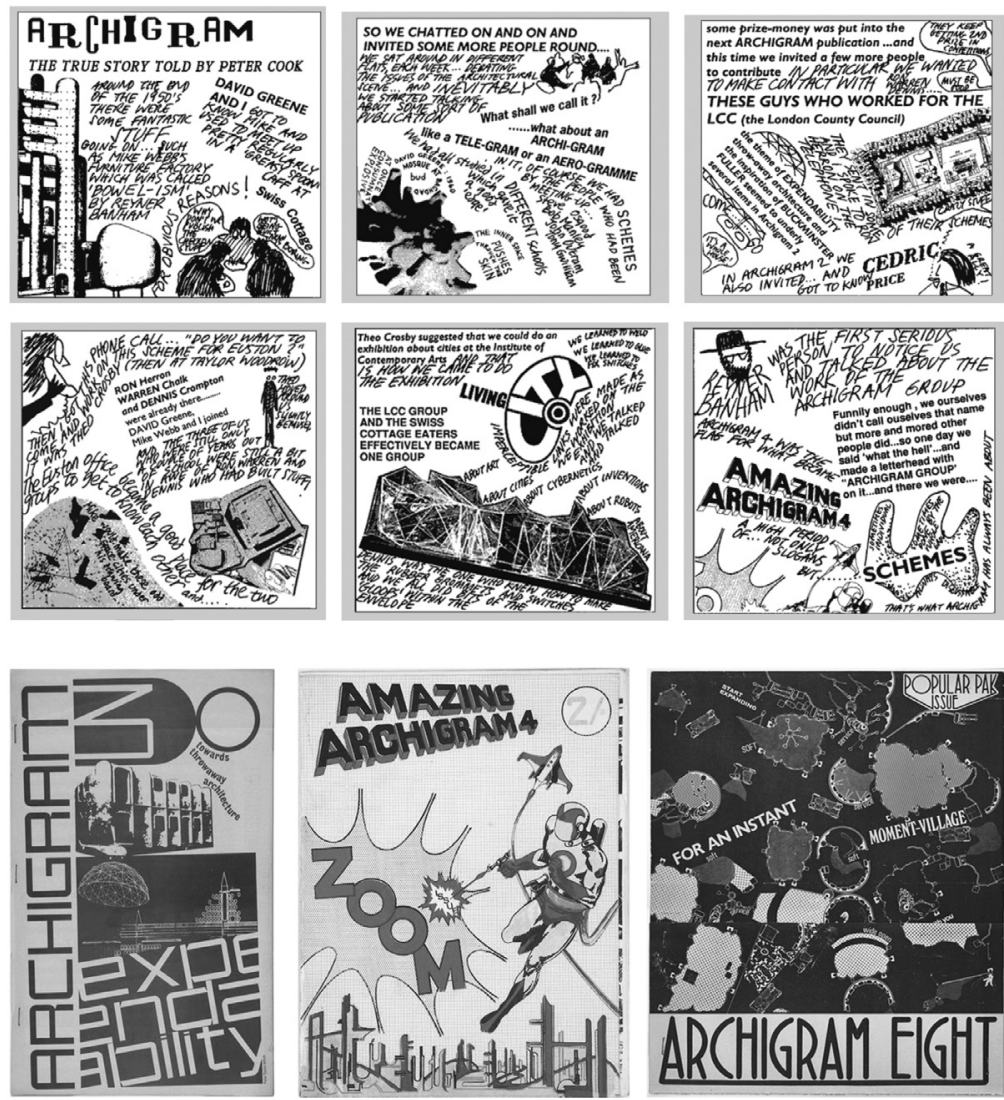

Figura 7. Publicaciones de Archigram. Arriba: “The true story of Archigram” by Peter Cook, en Archigram \#4. Abajo: Reproducción de tapas de revistas de diversos números de Archigram (números 3, 4 y 8 ). Se destaca el enfasis de Archigram en el poder retórico de la representación arquitectónica, y la importancia del dibujo como práctica de diseño y como herramienta de investigación.

La revista Archigram, publicada en nueve números y medio (de 1961 a 1974), fue en muchos aspectos su mayor contribución a los desarrollos arquitectónicos internacionales. En este sentido, el Arts Council del Reino Unido, al describir los elementos que conforman el archivo del movimiento, afirma que "el énfasis de Archigram en el poder retórico de la representación arquitectónica es significativo no solo para difundir sus propias ideas sino también por cómo ayudó a legitimar la importancia del dibujo como práctica de diseño y como herramienta de investigación" (Arts Council, 2019) (Ver Figura 7). 
El análisis extensivo de la experiencia y el legado de Archigram en la actualidad relata, entre otras cosas, que Peter Cook ya advertía resueltamente sobre la ausencia de arquitectura (en su aspecto más concreto) en los números 7 y 8 de la revista: "La materia concreta brutalista no tenía nada que ver en la construcción del futuro" (Sadler, 2005, p. 102).

Fue la exposición "Living City" la que en 1963 llevó al grupo a la popularidad. "Living City" fue una instalación diseñada por Archigram -la más destacada de ese año para el Institute of Contemporary Arts (ICA) - conformada por paneles triangulares, sostenidos por marcos de acero. Por medio de imágenes, textos, sonidos y luces, este "asalto a los 5 sentidos" (Maxwell, 1964, p. 99), envolvía físicamente a los visitantes para intentar transmitir una "visión de la ciudad como un ambiente que condiciona nuestras emociones" (Crosby y Bodley, 1963, p. 1). Fue producida por otros cinco arquitectos además de Warren Chalk (Peter Cook, Dennis Crompton, David Greene, Ron Herron y Michael Webb), colaborando con el diseñador de mobiliario Ben Fether y el diseñador gráfico Peter Taylor (Ver Figura 8).

Paralelo al abandono de las certezas de otras vanguardias (Sadler, 2003), "Living City" fue una declaración de fe de que la forma construida era solo la mitad de la experiencia arquitectónica: "Cuando llueve en Oxford Street, la arquitectura no es más importante que la lluvia, de hecho, el clima probablemente tenga más que ver con la pulsación de la Ciudad Viviente en ese momento".

"Living City" invitó a sus visitantes a practicar el voyeurismo. Se proporcionaron dos periscopios en escena que daban imágenes fugaces de chicas en Dover Street o de gente en un bar, fotografías de una chica glamorosa acomodando su ropa interior en la ciudad azotada por la lluvia, lanzando una mirada hacia atrás al observador - el fotógrafo-flâneur. El "Survival Kit" para estos microespacios, una suerte de catálogo de la exposición, estaba compuesto principalmente por productos de bajo consumo, cotidianos, de bolsillo, desechables, prohibidos y producidos en masa. Una colección de accesorios (cigarrillos, pañuelos, refrigerios, bebidas, anteojos de sol) de un flâneur equipado para pasear por la ciudad y experimentar su dinámica cultural y geográfica. El kit destacaba el dominio de un hombre joven, razonablemente rico, aparentemente libre de responsabilidad familiar, y que retrataba una masculinidad heterosexual bastante tradicional, lo que al principio parecía ser una invitación abierta y sin género a la aventura urbana (Sadler, 2003). Así, para Sadler, el "Survival Kit" fue una confesión franca del papel de la subjetividad masculina en la arquitectura, lo que hizo a la exhibición sorprendentemente subversiva para su época (Ver Figura 9).

La forma en que esta selección llegó a considerarse esencial para la vida en la ciudad en 1963 puede explicarse haciendo referencia a varios discursos actuales en ese momento, como el de la vida cotidiana, el existencialismo, el consumismo, el pop y, en última instancia, la supervivencia de la ciudad y del arquitecto. En contraposición al papel de 'unificador' y 'buen diseñador', los arquitectos de "Living City" estaban enseñando una apreciación del ruido y la improvisación que llenaban los espacios de la ciudad con vida. Si bien era posible distinguir algunos diseños (edificios extraños, como dibujos animados), el visitante del espectáculo o lector del catálogo se encontraría incluso con un desorden de la imagen que parecía poco arquitectónico. 